\title{
Refractory Anaemia with Ringed Sideroblasts associated with Marked Thrombocytosis - A Study of Four Cases
}

\author{
Barreira $\mathrm{R} *$, Ferreira $\mathrm{R} * *$ Cortez $\mathrm{J} *$, Gameiro $\mathrm{P} * * *$, Salazar I***, Silveira $\mathrm{M} *$ \\ *Serviço Patologia Clínica, Instituto Português de Oncologia Francisco Gentil EPE, Rua Prof Lima \\ Basto, 1099-023 Lisboa \\ **Serviço Patologia Clínica, Hospital Barlavento Algarvio, Portimão \\ ***Laboratório de Hemato-oncologia, Instituto Português de Oncologia Francisco Gentil EPE, Rua \\ Prof Lima Basto, 1099-023 Lisboa
}

Some hematological neoplasms share features of myelodysplastic syndromes (MDS) and myeloproliferative disorders (MPD), the World Health Organization (WHO) classification of hematopoietic neoplasms introduced a new separate category: myelodysplastic/myeloproliferative diseases (MDS/MPD). [1] Some patients may present diagnostic features of refractory anaemia with ringed sideroblasts (RARS) together with a markedly elevated platelet count $\left(>600 \times 10^{9} / \mathrm{L}\right)$. Provided that these patients do not have del(5q) nor abnormalities of chromosome 3 (3q21q26) and because features of both myelodysplastic and myeloproliferative processes are present, the WHO classification considers this a provisional entity belonging to the MDS/MPD, unclassifiable category. [1] The so-called provisional entity acquired sideroblastic anaemia associated with thrombocytosis/refractory anaemia with ringed sideroblasts (figure 1) associated with marked thrombocytosis (RARS-T) represents a heterogeneous disease, not only in terms of clinical and morphologic features, but also in terms of cytogenetic and molecular findings.

In view of the heterogeneity of this entity, we studied four patients with RARS-T (Table 1) in order to further characterize it, including cytogenetic analysis and molecular tests, namely the JAK2 V617F mutation, as recent reports show that JAK2 V617F is commonly detectable in such patients. $[2,3]$

We report four cases of RARS-T all having sustained thrombocytosis and sideroblastic erythropoiesis. In all four cases BCR/ABL gene rearrangement was not detected by FISH and BCR/ABL transcripts detection by nested PCR were also negative. Cytogenetic studies showed in Patient 1:

46,XY,ins(16;6)(p13;q2?5q2?4)[9]/46,XYins(16;6)(p13;q2?5q2?4), der(16)ins(16;6)(p13;5q2?4)[6]. Also the JAK2 V617F mutation was positive. In Patient 2 cytogenetic analysis of bone marrow revealed 46,XY,add(15)(p1?). JAK2 V617F mutation was negative. In Patients 3 and 4 cytogenetic studies were normal and JAK2 V617F mutation was negative. Cytogenetic studies were considerably different, being abnormal in two patients and the JAK2 V617F mutation was positive in one case. Albeit rare in true myelodysplastic syndromes, this gain-of-function mutation of JAK2 appears to be more common in RARS-T, reflecting its myeloproliferative features, namely marked thrombocytosis. These findings manifest the considerable heterogeneity of this entity, which apparently will continue to rely mainly on morphological (peripheral blood and bone marrow) criteria for diagnosis. 
Table 1:

\begin{tabular}{lllllll}
\hline Patient & Age & Sex & Hb & $\begin{array}{l}\text { Platelet } \\
\text { count }\end{array}$ & Leuc. & RS \\
\hline 1 & 85 & Male & 8.0 & 792.000 & 5.580 & 75 \\
2 & 52 & Male & 11.3 & 666.000 & 7.608 & 37 \\
3 & 82 & Male & 9.1 & 3.020 .000 & 21.410 & 76 \\
4 & 73 & Female & 7.6 & 661.000 & 5.350 & 77 \\
\hline
\end{tabular}

$\mathrm{Hb}$ : Haemoglobin $(\mathrm{g} / \mathrm{dl})$; Platelet count at diagnosis (x10\%/L); Leuc: Leucocytes $\left(\mathrm{x} 10^{9} / \mathrm{L}\right)$; RS: Ringed Sideroblasts (\%).

\section{References:}

[1] E.S. Jaffe, N.L. Harris, H. Stein,J. Vardiman, World Health Organization Classification of Tumours. Pathology and Genetics of Tumours of Hematopoietic and Lymphoid Tissues. IARC Press, Lyon, France, 2001.

[2] H. Szpurka, R. Tiu, G. Murugesan, S. Aboudola, E.D. His, K.S. Theil, M.A. Sekeres, J.P. Maciejewski, Blood 108. (2006) 2173-2181.

[3] Gattermann N, Billiet J, Kronenwett R, Zipperer E, Germing U, Nollet F, Criel A, Selleslag D, Blood. 108 (2007) 1334. 


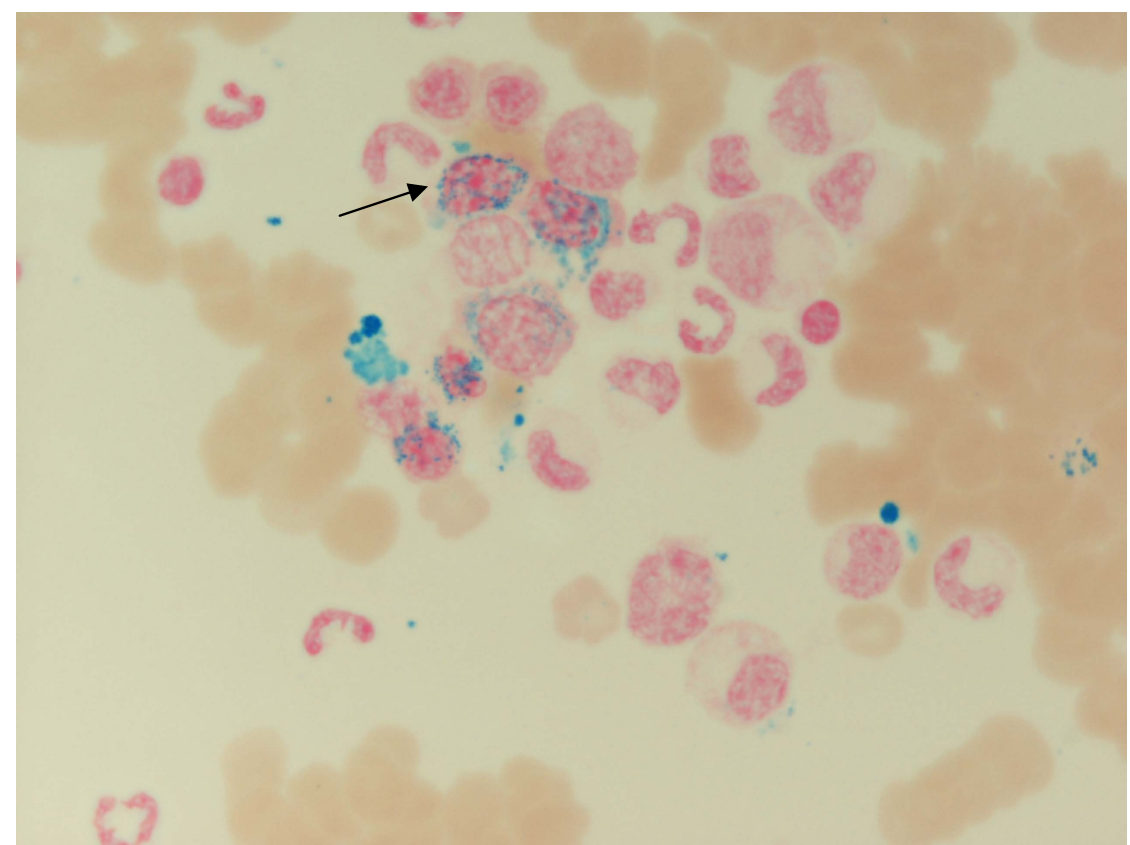

Figure 1. Ringed sideroblastos 